\title{
A CIÊNCIA JURÍDICA E O TEMPO: Perspectivas das Mutações dos Conceitos Estruturais do Ordenamento Jurídico Junto ao Correr das Épocas
}

\author{
http://dx.doi.org/10.21527/2176-6622.2020.53.28-39
}

Recebido em: 12/9/2019

Modificações solicitadas em: 20/1/2020

Aceito em: 26/2/2020

Arcio Milton Wailler

Especialista em Direito Constitucional pela Universidade Anhanguera (Uniderp). Especialista em Direito Processual Penal pela Universidade Anhanguera (Uniderp). Especialista em Direito Aplicado Lato Sensu pela Escola da Magistratura do Paraná (Emap). Bacharelado em Direito pela Pontifícia Universidade Católica do Paraná (PUCPR). Assessor Jurídico de Desembargador no Tribunal de Justiça do Paraná desde 2016. E-mail: arciomw@ outlook.com Currículo Lattes: http://lattes.cnpq.br/7549006388128605 ORCID iD: https://orcid.org/0000-00017509-525X.arciomw@outlook.com

Ricardo Cavedon

Doutorando em Direito das Relaç̃̃es Sociais pela Universidade Federal do Paraná (UFPR). Mestre em Direito Econômico pela Pontifícia Universidade Católica do Paraná (PUCPR). Pós-Graduação Lato Sensu e Bacharelado em Direito (PUCPR). Especialista em Direito Aplicado pela Escola da Magistratura do Paraná (Emap). Membro, aprovado como pesquisador, do Núcleo de Estudos em Direito Civil "Virada de Copérnico", do Programa de Pós-Graduação em Direito da UFPR. Pesquisador do grupo Justiça, Democracia e Direitos Humanos (PUCPR). Tem experiência na área de Direito, com ênfase em Direito Civil-Constitucional e Coletivo, atuando especialmente nos seguintes temas: construção histórica do pensamento jurídico, teoria geral dos direitos coletivos, tutela de bens jurídicos transindividuais, responsabilidade civil e criminal na violação dos direitos coletivos, entre outros temas. Autor de artigos jurídicos e do livro Teoria Geral dos Direitos Coletivos: Releitura da Racionalidade dos Direitos Fundamentais de Terceira Geração, publicado pela Editora Juruá. http://lattes.cnpq.br/5682648172792984. https://orcid.org/0000-0002-8049-3452. ricardo.cavedon@gmail.com

\section{RESUMO}

O presente trabalho tem o objetivo de analisar a influência do tempo na construção da significação normativa, com a mutação dos conceitos estruturais do Direito no decorrer das épocas, notadamente diante da atividade jurisprudencial e do tão propalado ativismo judicial. As alterações na significação normativa redundam na mutação constitucional e em diferentes definições para o fenômeno normativo de acordo com as novas exigências do tecido social. Nesse exercício, cabe analisar as consequências de quando se extrapolam os limites impostos pela concepção normativa trazidos pelo conceito de bloco de constitucionalidade, resultando no ativismo judicial, buscando entender os limites dessa atividade quando em voga a percepção de uma interpretação sistemática e evolutiva da norma jurídica. Dessa forma, serão perenemente estudados o conceito, os limites e as modalidades de alterações formais e informais da significação normativa, notadamente o aspecto mais controverso da mutação constitucional, para somente ao final, ainda com conclusões apenas parciais, buscar correlacionar com exemplos práticos de ativismo judicial pelo Supremo Tribunal Federal e uma possível ruptura com a noção atual de sistema jurídico aberto e circunscrito pelo conceito de bloco de constitucionalidade em sentido amplo.

Palavras-chave: Constituição Federal. Mutação constitucional. Ativismo judicial. Supremo Tribunal Federal.

\section{THE LEGAL SCIENCE AND THE TIME: PERSPECTIVES OF THE MUTATIONS OF THE STRUCTURAL} CONCEPTS OF LEGAL ORDINANCE TO THE RUNNING OF TIMES

\section{ABSTRACT}

This paper aims to analyze the influence of time in the construction of normative meaning, with the mutation of structural concepts of law throughout the ages, especially in view of jurisprudential activity and of the much-promoted judicial activism. Changes in normative significance result in constitutional change and new definitions for normative phenomenon according to new demands of social fabric. It's necessary to analyze the consequences of when the limits imposed by the normative conception brought by the concept of constitutionality block are extrapolated, resulting in judicial activism, seeking to understand the limits of this activity when the perception of a systematic and evolutionary interpretation of the legal norm is in vogue. This way, the concept, limits and most important modalities of formal and informal mutation of normative significance will be permanently studied, notably the most controversial aspect of constitutional change, so that only at the end, still yet only with partial conclusions, seek to correlate with practical examples of judicial activism by the Supreme Federal Court and a possible rupture with the current notion of an open legal system circumscribed by the concept of a constitutionality block, in a broad sense. Keywords: Federal Constitution. Constitutional mutation. Judicial activism. Federal Court of Justice.

\section{SUMÁRIO}

1 Introdução. 2 A mutação das normas jurídicas de acordo com o contexto temporal em que é interpretada. 3 Os limites imanentes da alteração constitucional por meio de processos informais. 4 As modalidades de mutação constitucional e a hipótese de mutação dos conceitos estruturais do ordenamento jurídico. 5 Exemplos de ativismo judicial por parte do Supremo Tribunal Federal e a noção de bloco de constitucionalidade. 6 Conclusão. 7 Referências. 


\section{INTRODUÇÃO}

A problemática que se pretende analisar no presente texto é a relação que a ciência jurídica possui com o tempo. O tempo é uma dimensão espacial que na Física é catalogada como que sobreposta às estruturas tridimensionais. O tempo é tido como uma realidade relacional e que possui características diversas das estruturas materiais, ostentando, acima de tudo, características de relatividade e relacionalidade. ${ }^{1}$

O tempo, segundo Albert Einstein, ${ }^{2}$ não é uniforme e não se desenvolve linearmente em diferentes contextos espaciais. Todo corpo de grande massa desacelera o tempo nas suas proximidades, tendo ao longo das épocas se percebido que há uma relacionalidade temporal diferente por entre as modificações da curvatura do espaço-tempo causados pela matéria. É dizer, o "sol e a terra modificam o espaço e o tempo em volta deles, como um corpo, ao mergulhar na água, desloca o líquido ao seu redor". ${ }^{3}$

Há igualmente uma relacionalidade entre o passar não linear do tempo ${ }^{4}$ e a velocidade (ou aceleração) de determinado observador. Segundo Carlos Rovelli, "ainda não sabemos como o tempo funciona de fato. A natureza do tempo talvez continue sendo o maior mistério de todos. Estranhos fios o conectam aos outros grandes mistérios não resolvidos: a natureza da mente, a origem do universo, o destino dos buracos negros, o funcionamento da vida". ${ }^{5}$ De fato, há um mistério imanente nas relações entre o tempo e o espaço, mas o fato é que dessa relação é possível se tirar conclusões probabilísticas que alcançam determinadas observações intrigantes, capazes de explicar alguns aspectos relacionados ao mundo em que vivemos. ${ }^{6}$

Da mesma forma, na Ciência Jurídica é possível afirmar que o tempo possui características diferenciadoras, capazes de modificar a estrutura normativa de conceitos jurídicos estruturais em plena conexão com as especificidades do tecido social. As alterações substanciais efetivamente existentes na realidade podem induzir pressupostos que venham a modificar a significação normativa, não só por agregar elementos culturais ou sociais inéditos e antes não percebidos, mas também por alterar os pressupostos inerentes à atividade interpretativa.

A forma como se interpreta um texto legal pode levar em conta duas perspectivas, ou atribuindo relevância à vontade do legislador (à época da construção legislativa) ou consistindo fundamento da intepretação à vontade atual do intérprete (no momento presente de quando é feita a interpretação). Nas duas situações há um fato em comum. Sempre é possível entender que a realidade social impregna o significado da norma jurídica de acordo com o contexto da interpretação, relacionando-se a interpretação com o contexto temporal em que o texto é interpretado.

\footnotetext{
“(...) Paro e não faço nada. Nada acontece. Não penso em nada. Ouço o passar do tempo. O tempo é isso. Familiar e íntimo. Sua força nos arrasta. A sucessão de segundos, horas e anos nos projeta na vida, depois nos arrasta para o nada... Vivemos nele como peixes na água. $O$ que somos, somos no tempo. Sua cantiga alimenta, descortina o mundo, perturba, assusta, acalenta. O universo se transforma levado pelo tempo, segundo a ordem do tempo." (ROVELLI, Carlos. A ordem do tempo. Tradução Silvana Cobucci Leite. Rio de Janeiro: Ed. Objetiva, 2017. p. 10).

Nesse sentido: EINSTEIN, Albert. Einstein's manuscript on the special theory of relativity. In: KLEIN, M.; KOX. A. J.; RENN, J.; SCHULMANN, R. (ed.). The collected papers of Albert Einstein. Princeton: Princeton University Press, 1995 [1912]. v. 4: The Swiss years: writings 19121914. p. 9-108. STACHEL, John. Einstein's 1912 manuscript as a clue to the development of special relativity. Disponível em: http://dx.doi. org/10.1590/S1678-31662005000400003. Acesso em: 28 fev. 2019.

3 ROVELLI, Carlos. A ordem do tempo. Tradução Silvana Cobucci Leite. [S.I.]: Ed. Objetiva, 2017. p. 19.

4 “(...) Em termos técnicos, diz-se que Einstein compreendeu que não existe a "simultaneidade absoluta", ou seja, não existe um conjunto de eventos no Universo que sejam todos existentes "agora". O nosso "agora" existe apenas aqui. O conjunto de eventos no Universo não pode ser descrito corretamente como uma sucessão de presentes, um subsequente ao outro; sua estrutura é mais complicada..." (ROVELLI, Carlos. A realidade não é o que parece: a estrutura elementar das coisas. Tradução Silvana Cobucci Leite. Rio de Janeiro: Ed. Objetiva, 2017. p. 49).

5 "O aumento do conhecimento levou a uma lenta desintegração da noção de tempo. O que denominamos "tempo" é uma complexa coleção de estruturas e de camadas. À medida que o estudo do tempo avançou, essas camadas se perderam, uma depois da outra, um pedaço após o outro". (cf. ROVELLI, Carlos. A ordem do tempo. Tradução Silvana Cobucci Leite. [S.I.]: Ed. Objetiva, 2017. p. 12).

6 Vide nesse sentido a teoria da relatividade geral de Albert Einstein, e os modelos adstritos à mecânica quântica, notadamente a sua unificação pertencente à teoria das cordas ou teoria de tudo, explicadas pelo renomado físico estadunidense Edward Witten.
} 
Daí porque se afirmar que as normas jurídicas possuem uma estrutura dinâmica, contudo sua modificação somente se verifica quando em contato com alterações substanciais efetivamente existentes no tecido social. A letra da lei em sua abstração com o correr do tempo permanece a mesma, mas, quando invocada sua significação normativa para aplicabilidade em um caso concreto futuro, por vezes agrega, em sua dimensão normativa, as novas estruturas que preenchem a realidade social no momento futuro de sua interpretação.

Os elementos normativos adicionais à significação normativa acabam por agregar uma nova contextualização e modificar sua relacionalidade com a Ciência Jurídica numa perspectiva sistemática. Ou seja, o tempo em sua dimensão espacial faz a norma se modificar, alterando sua significação normativa, sem, contudo, ostentar alteração em sua estrutura formal.

Nessa perspectiva é que se busca estudar as características e definições da mutação das normas estruturais do Direito, para além da mera definição doutrinária, razão pela qual será analisado o impacto do tempo na Ciência Jurídica e a reconstrução de significado normativo de acordo com as exigências dinâmicas da realidade e do tempo presente.

\section{A MUTAÇÃO DAS NORMAS JURÍDICAS DE ACORDO COM O CONTEXTO TEMPORAL EM QUE É INTERPRETADA}

O ordenamento jurídico possui uma estrutura dinâmica que, na mesma medida que o universo, encontra-se em plena e permanente expansão ${ }^{7}$ e em constante desenvolvimento e alteração, notadamente quando analisamos a atividade jurisprudencial atualmente muito ligada às percepções do ativismo judicial. Para que seja capaz de acompanhar as mudanças socioeconômicas, a ciência do Direito dobra-se e se retorce, moldando-se às vicissitudes sociais. A cada alteração substancial da realidade encontra novos pressupostos e justificações mais acertadas para seus postulados. Sempre à medida que o tempo se altera, a realidade social subjacente é significativamente transformada.

No âmbito constitucional, como mecanismos formais de alteração da Carta Magna, é possível apontar conceitualmente a reforma constitucional - que pode abranger tanto a revisão constitucional, tida como possível pela previsão expressa no seu texto (artigo 3ำ, do Ato das Disposições Constitucionais Transitórias), ${ }^{8}$ como a emenda constitucional, disposta no artigo 60 da Constituição da República. A revisão constitucional trata-se de uma norma de eficácia exaurida, pois seus efeitos já se esvaíram cinco anos após a promulgação, portanto, no ano de 1993. A emenda constitucional, contudo, a teor do artigo 60 da Constituição Brasileira, pode ocorrer mediante proposta ou do presidente da República ou de mais de um terço dos membros da Câmara dos Deputados ou do Senado Federal, ou ainda, de mais da metade das Assembleias Legislativas das unidades da Federação, manifestando-se, cada uma delas, pela maioria relativa de seus membros. ${ }^{9}$

\footnotetext{
“Einstein agarrou-se a uma tese inaceitável para não acreditar no que suas próprias equações lhe diziam. Chegou a cometer erros absurdos de Física (não percebeu que a solução da equação que estava estudando era instável) para não aceitar a evidência do que sua teoria prevê: que o Universo está em contração ou em expansão. Por fim, foi obrigado a ceder: é a sua teoria que está certa, e não ele". (ROVELLI, Carlos. A realidade não é o que parece: a estrutura elementar das coisas. Tradução Silvana Cobucci Leite. Rio de Janeiro: Ed. Objetiva, 2017. p. 71).

8 Conforme o artigo 3ㅇ do Ato das Disposições Constitucionais Transitórias "A revisão constitucional será realizada após cinco anos, contados da promulgação da Constituição, pelo voto da maioria absoluta dos membros do Congresso Nacional, em sessão unicameral”.

9 Na democracia representativa, a soberania popular é exercida pelo sufrágio universal e pelo voto direto e secreto, com valor igual para todos dos mecanismos tradicionais de seu exercício, por meio dos representantes eleitos pelo povo, também há instrumentos de participação direta, como é o caso do plebiscito, do referendo e da iniciativa popular.
} 
Não obstante o artigo 61, §2ㅇ da Constituição da República de $1988^{10}$ admitir a apresentação de Projeto de Lei por meio de iniciativa popular, não é possível no âmbito federal a proposta de emenda à Constituição mediante iniciativa popular, ${ }^{11}$ porquanto se entenda que o rol dos legitimados previsto no artigo 60 da Constituição Federal seja taxativo, não é viável uma interpretação extensiva do seu artigo 61, §2으, dado que o artigo é expresso em restringir a iniciativa popular unicamente aos Projetos de Lei. As leis ainda podem ser alteradas por outras leis, pois segundo artigo 1ㅇ, $\S 4$ 으, da Lei de Introdução às Normas do Direito Brasileiro, ${ }^{12}$ "as correções a texto de lei já em vigor consideram-se lei nova".

Como mecanismos informais de alteração legislativa, por outro lado, é possível identificar o que a doutrina moderna vem denominando de mutação constitucional - ou de mutação das normas jurídicas estruturantes no ordenamento jurídico, tido como um instrumento de atualização das normas jurídicas e constitucionais, quando, embora não seja necessário que a norma sofra alterações formais por meio de projeto ou emenda legislativa, é necessário que haja uma perene interconexão com as múltiplas exigências da realidade social. Há casos em que o Judiciário interpreta a legislação para além de seu sentido literal e teleológico, podendo-se identificar que esse ativismo judicial adstrito à extrapolação dos limites objetivos da função interpretativa por vezes pode ensejar uma mutação inconstitucional das normas jurídicas.

A estabilidade da Constituição da República é advinda da rigidez de suas normas, e da dificuldade, notadamente quando envolvem princípios jurídicos estruturais, de alteração formal de estruturas valorativas essenciais. A Carta é explícita em não admitir que seja objeto de deliberação a proposta de emenda tendente a abolir a forma federativa de Estado, o voto direto, secreto, universal e periódico, a separação dos poderes, e ainda, os direitos e garantias individuais. As cláusulas pétreas são limites imanentes à rigidez constitucional e garantem a estabilidade de nosso ordenamento jurídico, entretanto a existência e aplicação da rigidez constitucional não possui o condão de tornar eterno ou imutável as normas dispostas na Constituição da República.

Isso porque o texto constitucional, com o passar do tempo, precisa ir se adaptando às mudanças que ocorrem na realidade social, sendo certo que, em regra, referidas adaptações ocorrem por um processo formal e difícil, com alguns requisitos específicos, ${ }^{13}$ o que acaba gerando um obstáculo para o legislador no poder de reforma. Além das cláusulas pétreas também não podem ser objeto de nova deliberação para alteração formal da Constituição, a matéria constante de proposta de emenda já rejeitada ou havida por prejudicada na mesma sessão legislativa (artigo 60, §5ㅇda Constituição da República).

Assim sendo, existe a possibilidade de que ocorram alterações não formais na Constituição e nas normas jurídicas em geral, por um processo informal ou indireto, o que se dá pela denominada teoria da mutação constitucional. De forma sintética, mutação constitucional é a interpretação modificativa da Constituição e das normas jurídicas estruturais sem revisões formais do texto escrito legislado. Trata-se do fenômeno de alteração da significação normativa a partir da interpretação, sem que para tanto as normas constitucionais se modifiquem formalmente no procedimento legislado das revisões ou das emendas textuais.

Em outras palavras, a mutação constitucional ocorre por meio de processos informais de modificação do significado da Constituição sem alteração do seu texto. Altera-se o sentido da norma constitucional sem modificar as palavras que a expressam. Esta mudança pode ocorrer com o surgimento de um novo costume que se espelhe na seara constitucional ou pela via interpretativa. Também no Supremo Tribunal Federal a interpretação judicial é reconhecida como "instrumento de mutação informal da Constituição".

\footnotetext{
${ }^{10}$ Artigo 61 (...) §2ํㅡ A iniciativa popular pode ser exercida pela apresentação à Câmara dos Deputados de projeto de lei subscrito por, no mínimo, 1\% do eleitorado nacional, distribuído pelo menos por cinco Estados, com não menos de três décimos por cento dos eleitores de cada um deles.

${ }^{11}$ No âmbito do poder constituinte derivado, não obstante, é possível a previsão, conforme entendimento da Suprema Corte, a assentar que "a iniciativa popular de emenda à Constituição Estadual é compatível com a Constituição Federal, encontrando fundamento no artigo 1 으, parágrafo único, no artigo 14, II e III e no artigo 49, VI, da CF/88. Embora a Constituição Federal não autorize proposta de iniciativa popular para emendas ao próprio texto, mas apenas para normas infraconstitucionais, não há impedimento para que as Constituições Estaduais prevejam a possibilidade, ampliando a competência constante da Carta Federal” (Cf. STF. Plenário. ADI 825/AP, Rel. Min. Alexandre de Moraes, julgado em 25/10/2018 - Info 921).

${ }^{12}$ Art. $1^{\circ}(\ldots) \S 4^{\circ} \S 4^{\circ}$ As correções a texto de lei já em vigor consideram-se lei nova.

${ }^{13}$ Art. 60. (...) §2ㅇ A proposta será discutida e votada em cada Casa do Congresso Nacional, em dois turnos, considerando-se aprovada se obtiver, em ambos, três quintos dos votos dos respectivos membros. §3으 A emenda à Constituição será promulgada pelas Mesas da Câmara dos Deputados e do Senado Federal, com o respectivo número de ordem.
} 
As mutações constitucionais operam verdadeiro renascimento de alguns dispositivos ao permitirem que estes sejam relidos. ${ }^{14} \mathrm{O}$ poder é intitulado "difuso" porque nunca se sabe de modo preciso "quando" e "como" se iniciou o processo de restruturação e efetivação das informais transformações hermenêuticas que vão rejuvenescer a Constituição Federal, adaptando-a às mudanças sociais que o dinamismo da vida fática ocasionou.

Mutações constitucionais derivam, principalmente, do modo como se exerce ou se deixa de exercer o poder estatal regulado na Constituição Federal. Manifestam-se nas práticas legislativas, jurisprudenciais e administrativas mediante as quais se vai alterando o original sentido da Constituição, muitas vezes ampliando ou restringindo o alcance das suas normas, sem reformas constitucionais. Por intermédio dessas práticas, tanto as disposições normativas quanto as lacunas da Constituição adquirem novos sentidos, de maneira a adaptá-las às forças e necessidades políticas que surgem no decurso do tempo.

Neste sentido, Karl Loewenstein define mutação constitucional como fenômeno por meio do qual: ${ }^{15}$

É produzida uma transformação na configuração real do poder político, da estrutura social ou do equilíbrio de interesse sem que seja refletida tal transformação no documento constitucional: o texto da Constituição permanece intacto. Esse tipo de mutação constitucional ocorre em todos os Estados dotados de uma Constituição escrita e é muito mais frequente que as reformas constitucionais formais.

Por sua vez, conforme palavras de José Afonso da Silva, a mutação constitucional: ${ }^{16}$

Consiste num processo não formal de mudanças das Constituições Rígidas, por via da tradição, dos costumes, de alterações empíricas e sociológicas, pela interpretação judicial e pelo ordenamento de estatutos que afetem a estrutura orgânica do estado.

No mesmo sentido, Anna Cândida da Cunha Ferraz discorre sobre a mutação constitucional: ${ }^{17}$

A expressão mutação constitucional é reservada somente para todo e qualquer processo que altere ou modifique o sentido, o significado e o alcance da Constituição sem contrariá-la; as modalidades de processos que introduzem alteração constitucional, contrariando a Constituição, ultrapassando os limites constitucionais fixados pelas normas, enfim, as alterações inconstitucionais, são designadas por mutações inconstitucionais. Assim, em síntese, a mutação constitucional altera o sentido, o significado e o alcance do texto constitucional sem violar-lhe a letra e o espírito. Essa característica fundamental da noção de mutação constitucional é que merece, por ora, ser ressaltada. Trata-se, pois, de mudança constitucional que não contraria a Constituição, ou seja, que, indireta ou implicitamente, é acolhida pela Lei Maior.

Quanto à hierarquia normativa, embora possam servir de parâmetro de controle das normas infraconstitucionais, as mutações constitucionais subordinam-se às reformas constitucionais. Isso porque, como o limite da interpretação é o texto, novas alterações formais acabam por prevalecer sobre anteriores alterações informais da Constituição.

Por fim, como exemplo de incidência do fenômeno no Brasil, podemos citar as seguintes passagens do Supremo Tribunal Federal: a) a renovação do entendimento (HC 82.959/SP) quanto ao artigo 50, inciso XLVI, da Constituição Federal de 1988, o que permitiu à Corte rever sua antiga jurisprudência firmada no sentido da constitucionalidade da vedação à progressão de regime nos crimes hediondos; ${ }^{18}$ b) a superação do entendimento quanto à autonomia municipal para fixar o número de vereadores, instituindo-se rígidos critérios aritméticos diante da população dos respectivos municípios, a despeito de inalterado o texto do artigo 29, inciso IV, da Constituição Federal de 1988 (RE 197.917/SP), até que sobreveio a Emenda Constitucional $n^{\circ}$ 58, de 23/9/2009.

\footnotetext{
${ }^{14}$ Segundo Uadi Lammêgo Bulos, o poder é intitulado difuso "porque não vem formalizado nas constituições". (Curso de Direito Constitucional. São Paulo: Saraiva, 2007. p. 316).

${ }^{15}$ LOEWENSTEIN, Karl. Teoria de la constitución. Trad. Alfredo G. Anabitarte. Barcelona: Ariel, 1965, apud KUBLISCKAS, Wellington Márcio. Emendas e Mutações Constitucionais: análise dos mecanismos de alteração formal e informal da Constituição Federal de 1988. São Paulo: Atlas, 2009. p. 72.

${ }^{16}$ SILVA, José Afonso da. Curso de Direito Constitucional positivo. 33. ed. atual. São Paulo. Malheiros, 2010, p. 61-62.

17 FERRAZ, Anna Cândida da Cunha. Processos informais de mudança da Constituição. 1. ed. São Paulo. Max Limonad, 1986. p. 10.

${ }^{18}$ Art. $2^{\circ}, \S 1^{\circ}$ da Lei ${ }^{\circ} 8.072 / 1990$. A pena por crime previsto neste artigo será cumprida inicialmente em regime fechado.
} 
Pode-se entender, então, que a mutação constitucional consiste na alteração do significado, sentido e alcance das normas constitucionais, sendo certo que referidas alterações visam a adaptar a Constituição com a realidade social e não ensejam reformas no seu texto.

\section{OS LIMITES IMANENTES DA MUTAÇÃO CONSTITUCIONAL POR MEIO DE PROCESSOS INFORMAIS}

Em decorrência de a mutação constitucional consistir num processo informal de mudança da Constituição, indagam-se quais seriam os seus limites de alteração dado o grau de flexibilidade que se atribui ao intérprete na criação de um novo significado para aquele texto.

Essa indagação deve ser analisada com muita cautela, pois a aplicação de tal instituto de forma equivocada pode importar numa ilegitimidade legislativa ao intérprete, contrariando a própria Constituição que dispõe sobre a separação dos poderes.

Logo, é necessário que determinados parâmetros sejam respeitados, pois deixando somente a cargo da consciência do intérprete a realização de mudanças no sistema normativo, mesmo que não altere expressamente o texto constitucional, estaria ocorrendo uma violação da segurança jurídica. Nesse sentido, o fenômeno da mutação constitucional deve estar em harmonia com a Constituição Federal, pois, caso contrário, estaríamos diante de uma mutação inconstitucional.

Sobre o tema, Nadja Machado Botelho dispõe que "apesar da dificuldade de estabelecer limites à mutação constitucional, é certo que esta esbarra no texto da Constituição e que a norma em questão consubstancia uma regra que deixa pouco espaço para a interpretação, não podendo haver mutação que retire toda a eficácia de determinado dispositivo constitucional". ${ }^{19}$

Deste modo, vários juristas indicam algumas diretrizes para a aplicação da mutação constitucional. Como exemplo, Botelho cita como limite à mutação constitucional as cláusulas pétreas, dispondo que: ${ }^{20}$

Mesmo sujeitas às suas próprias mutações, as cláusulas pétreas também se afiguram como limites à mutação constitucional, de maneira que a alteração de sentido e alcance dos dispositivos constitucionais não poderá atingir o conteúdo essencial nem favorecer a abolição do núcleo duro da Constituição.

Em outras palavras, Botelho esclarece que a mutação constitucional não pode atingir a essência das cláusulas pétreas e nem pretender a sua extinção, contudo, pode a mutação ampliar o seu alcance e enriquecer o seu conteúdo, pois o que pode ser atingido por meio de reforma pode também ser atingido por meio de mutação.

Além disto, Botelho identifica outros três limites essenciais que devem ser respeitados pela mutação constitucional, quais sejam: a) a mutação deve ser limitada aos sentidos possíveis do texto constitucional; b) a mutação deve decorrer de legítima transformação social; c) a mutação não deve avançar no campo próprio da reforma constitucional. ${ }^{21}$

Por fim, cumpre destacar que a mutação constitucional, na maioria das vezes, se dá por meio do poder Judiciário, razão pela qual Carlos Henrique Ramos estabelece, ainda, os seguintes limites ao referido poder: a) vinculação às significações possíveis de um enunciado normativo; b) exigência de motivação racional das decisões judiciais; c) autoconcepção judicial, não podendo o juiz atuar em questões de competência do legislativo. ${ }^{22}$

Dessa forma, verifica-se que não pode o intérprete alterar deliberadamente a Constituição Federal, ressaltando-se que ele só deve aplicar a mutação constitucional quando a legítima transformação da realidade social o exigir, não podendo ultrapassar, contudo, o limite permitido pelo texto constitucional.

\footnotetext{
${ }_{19}$ BOTELHO, Nadja Machado. Mutação constitucional: a Constituição viva de 1988. Rio de Janeiro: Lumen Juris, 2011. p. 160.

20 Ibid., p. 39-40.

${ }^{21}$ Ibid., p. 34.

${ }^{22}$ RAMOS, Carlos Henrique. Mutação constitucional: Constituição e identidade constitucional evolutiva. Curitiba: Juruá, 2013. p. 150-151.
} 


\section{Debate}

\section{4) AS MODALIDADES DE MUTAÇÃO CONSTITUCIONAL E A HIPÓTESE DE MUTAÇÃO DOS CONCEITOS ESTRUTURAIS DO ORDENAMENTO JURÍDICO}

Não há consenso quanto à divisão do fenômeno da mutação constitucional por categorias, mesmo porque não seria possível exaurir todas as possibilidades e as categorias pelas quais aparecem as mudanças informais da Constituição.

Assim, tendo em vista que a doutrina apresenta uma variação considerável de modalidades acerca do instituto, será visto adiante, de forma sucinta, as duas principais categorias e o que entendem os doutrinadores a respeito delas.

Quanto à legitimidade das mutações constitucionais operadas por via interpretativa, Canotilho sustenta que uma rigorosa compreensão da estrutura normativo-constitucional conduz, em princípio, à exclusão de mutações constitucionais operadas nesta hipótese, o que não significa que a Constituição deva ser compreendida como um texto estático e rígido, indiferente às alterações da realidade constitucional. ${ }^{23}$

A interpretação judicial da Constituição, todavia, por sua alta relevância, tem sido considerada, pela doutrina, como a de maior importância dentre as espécies de mutação constitucional. A relevância atribuída a esta modalidade de interpretação deve, em grande parte, ser atribuída à repercussão das decisões judiciais e às características de que se reveste essa modalidade de mutação constitucional.

Revela-se a interpretação judicial nas decisões - sentenças, acórdãos - que aplicam a Constituição ao caso concreto, o que, segundo Anna Cândida da Cunha Ferraz, pode ocorrer de dois modos: a) mediante a aplicação pura e simples da norma constitucional para solucionar a lide; b) nos casos em que o exercício da função jurisdicional visa ao controle de constitucionalidade de leis ou atos normativos. ${ }^{24}$

Em tais casos, o exercício da jurisdição constitucional não implica controle de constitucionalidade de lei ou ato normativo, e sim, em aplicação pura e simples da norma constitucional, para solucionar a lide. Forma-se um litígio constitucional porque a pretensão funda-se na norma constitucional e é com a aplicação desta que o conflito será solucionado. Assim sendo, a tutela jurisdicional vai recair na lide que se formou em virtude da relação jurídico-constitucional. ${ }^{25}$

Ainda, a referida autora apresenta alguns traços peculiares no que concerne ao exercício da atividade interpretativa pelos órgãos judiciários, quais sejam: a) é obrigatória, tendo em vista que o juiz não pode deixar de decidir o litígio que envolva matéria constitucional, salvo se tal competência não lhe é atribuída; b) é primária, pois caracterizam-se por serem atos só fundados na Constituição; c) só atua mediante provocação e em casos concretos, haja vista que interpretação da Constituição, pelos órgãos judiciais, só se efetiva quando há processo judicial; d) é, em regra, definitiva, pois de um lado a decisão da autoridade administrativa e lei que se destinam a aplicar a Constituição podem ser anuladas por decisão do Judiciário, enquanto que, de outro lado, as decisões de juízes e tribunais inferiores poderão ser reformuladas pela Corte dotada de autoridade final; e) é mutável, ou seja, a interpretação constitucional judicial pode ser válida e regularmente alterada pela própria Corte Constitucional; f) é vinculante, pois se não houver no ordenamento jurídico texto legal ou constitucional que lhe atribua força vinculante, a interpretação constitucional apenas poderá influir como elemento de conviç̧ão. ${ }^{26}$

Finalmente, imperioso ressaltar que a mutação constitucional por meio da interpretação judicial deu ensejo a duas correntes acerca da competência para "legislar" sobre matéria constitucional. A primeira corrente defende que o referido fenômeno seria antidemocrático, haja vista ser exercido por um órgão não eleito pelo povo. Por sua vez, a segunda corrente entende que o referido fenômeno é legítimo, considerando que os Tribunais Constitucionais são compostos por membros que foram escolhidos justamente pelos representantes eleitos pelo povo, razão pela qual a decisão destes seria aceita pela sociedade. ${ }^{27}$

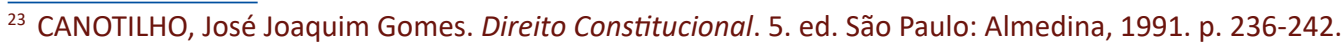

${ }^{24}$ FERRAZ, Anna Cândida da Cunha. Processos Informais de Mudança da Constituição, 1. ed. São Paulo: Editora Max Limonad, 1986. p. 104.

${ }^{25}$ Ibid., p. 104.

${ }^{26}$ Ibid., p. 116-121.

27 MORAES, Alexandre de. Direito constitucional. 20. ed. São Paulo: Atlas, 2006. p. 129.
} 
Dessa forma, o que se percebe é que a mutação constitucional por meio da interpretação judicial possui grande relevância no que diz respeito ao processo informal de alteração da Constituição, tendo em vista que os Tribunais Constitucionais podem alterar o sentido, alcance e significado das normas constitucionais para que haja a adaptação da Carta Maior à realidade social.

O costume penetra no modo jurídico quando, através dele, se manifesta uma norma com pretensão de império inexorável, regendo, portanto, como se fosse lei, isto é, sendo considerado juridicamente obrigatório. Logo, o costume é uma norma jurídica sobre determinada relação de fato e resultante da prática diária e uniforme que lhe dá força de lei.

Dois elementos estão contidos na conceituação anterior, quais sejam: objetivo e subjetivo. Em síntese, o requisito objetivo consiste na prática reiterada de determinado ato, enquanto o requisito subjetivo consiste na convicção generalizada de que determinado ato deve ser praticado.

Assim, segundo Bulos, os costumes constitucionais podem apresentar-se de três maneiras: ${ }^{28}$ a) costume secundum legem: é o costume que já está previsto na lei, sendo certo que, nesta modalidade, o costume desencadeia alterações no conteúdo das normas constitucionais por meio da interpretação; b) costume praeter legem: é aquele que complementa a lei (caráter supletivo), ou seja, o costume preenche/complementa lacunas, sanando, assim, omissões e descuidos imanentes à atividade legislativa; c) costume contra legem: é o costume contrário à lei, razão pela qual, diante da rigidez e da força normativa da Constituição Federal, não pode ser invocado para descumprimento da Carta Maior, bem como não enseja a revogação de seus preceitos.

Ainda, segundo Cláudio Pereira de Souza Neto, são admissíveis os costumes: ${ }^{29}$ a) praeter constitutionem: também conhecido como integrativo, uma vez que preenche as lacunas constitucionais; b) secundum constitutionem: também conhecido como interpretativo, posto que é adotada uma interpretação da Constituição porque ela é "endossada por costume jurídico cristalizado".

Por sua vez, segundo Anna Candida da Cunha Ferraz, os costumes constitucionais decorrem da própria Constituição: ${ }^{30}$

Se a Constituição nasce para ser efetivamente aplicada, desse princípio decorre logicamente que, diante da obscuridade ou inexistência de norma que ponha em ação matéria constitucional, os órgãos ou poderes constituídos devem atuá-las. É uma decorrência lógica da Constituição encontrarem os poderes constituídos meios de atuá-la validamente. Nessa linha de raciocínio o costume constitucional forma-se por decorrência lógica da própria Constituição".

Por fim, imperioso ressaltar que parte da doutrina entende não existir o costume constitucional diante de Constituições rígidas, uma vez que, em virtude do princípio da supremacia, não há espaço para qualquer modalidade de costume, haja vista que toda norma, inclusive a não escrita, cede diante da superioridade constitucional. ${ }^{31}$

\section{EXEMPLOS DE ATIVISMO JUDICIAL POR PARTE DO SUPREMO TRIBUNAL FEDERAL E A NOÇÃO ATUAL DE BLOCO DE CONSTITUCIONALIDADE EM SENTIDO AMPLO}

A expressão bloco de constitucionalidade surgiu no Direito francês, ${ }^{32}$ no início dos anos 70, e ostentou uma evolução no seu conteúdo. A ideia do conceito, segundo Louis Favoreu e Francisco Rubio Llorente, foi buscar uma determinação aceitável das normas de referência ou parâmetros suscetíveis de regular a repar-

\footnotetext{
${ }_{28}$ BULOS, Uadi Lammêgo, Do costume constitucional, 1996. p. 104-105.

${ }^{29}$ SOUZA NETO, Cláudio Pereira de. Direito Constitucional: teoria, história e método de trabalho. 1a reimpressão: Belo Horizonte: Editora Fórum, 2013. p. 351.

${ }^{30}$ FERRAZ, Anna Candida da Cunha. Processos informais de mudança da Constituição. 1. Ed. São Paulo+ Editora Max Limonad, 1986. p. 185.

31 Ibid., p. 183.

32 "En la doctrina francés, la expresión bloc de constituonnalité se utiliza para designar el conjunto de normas que el Conseil Constitutionnel aplica en el control previo de constitucionalidad de las leyes y de los reglamentos parlamentarios. Este conjunto, al que ya alude una decisión de 1966, está integrado e todo caso por la Constitución y, por remisión del Preámbulo de ésta, la Declaración de Derechos del Hombre y del Ciudadano de 1789 y el Preámbulo de la Constitución de 1946, que es realmente también una declaración de derechos, sobre todo de caráter social" (FAVOREU, Louis; LLORENTE, Francisco Rubio. El bloque de la constitucionalidad (simposium franco-español de Derecho constitucional). Sevilla: Editorial Civitas; Universidad de Sevilla, 1991. p. 105).
} 
tição de competência entre o Estado e as comunidades autônomas internacionais; a ideia de bloco invoca a de solidez, de unidade, um bloco é como um conjunto que não pode ser cindido ou dividido, e isso significa a sua importância e necessidade de continuação, perpetuação de sua existência ao longo das épocas. O bloco de constitucionalidade, portanto, na lição de Favoreu e Llorente, é integrado por elementos principais e marginais, consistentes os primeiros nas normas constitucionais e nas declarações de direitos humanos que possuem o mesmo status da Carta Constitucional, e os segundos, nos princípios fundamentais reconhecidos pelas leis da República. ${ }^{33}$

Assim, a expressão bloco de constitucionalidade deve servir de parâmetro para o ativismo judicial, podendo-se conceituar este como uma decisão que não respeita os limites impostos pela própria lei, ou seja, é a extrapolação da função jurisdicional, uma atitude exacerbada do poder Judiciário.

Em outras palavras, entende-se que o ativismo judicial seria a ingerência do poder Judiciário nos outros poderes no intuito de intensificar os valores e os objetivos constitucionais. Sua percepção ocorre na declaração de inconstitucionalidade de normas oriundas do Legislativo, na demarcação de condutas ao poder público, bem como na interpretação da Constituição, sem anuência do legislador, em situações não previstas pela Lei Maior.

Neste sentido, Elival da Silva Ramos conceitua o ativismo judicial como sendo a extrapolação dos limites impostos ao poder Judiciário quando da sua atuação: ${ }^{34}$

Não se trata do exercício desabrido da legiferação (ou de outra função não jurisdicional), que, aliás, em circunstâncias bem delimitadas, pode vir a ser deferido pela própria Constituição aos órgãos superiores do aparelho judiciário, e sim da descaracterização da função típica do poder Judiciário, com incursão insidiosa sobre o núcleo essencial de funções constitucionalmente atribuídas a outros poderes.

No mesmo sentido, Luís Roberto Barroso entende que a ideia do ativismo judicial está associada a uma atuação mais intensa do poder Judiciário, na concretização dos valores e fins constitucionais, com maior interferência no espaço dos poderes Executivo e Legislativo. Além disto, para ele o ativismo judicial é caracterizado: a) pela aplicação direta da Constituição a situações não expressamente contempladas em seu texto, e independentemente da manifestação do legislador ordinário; b) pela declaração de inconstitucionalidade dos atos normativos emanados do legislador, com base em critérios menos rígidos que os de patente e ostensiva violação da Constituição; c) pela imposição de condutas e abstenções ao poder público, notadamente em matéria de políticas públicas. ${ }^{35}$

Barroso aduz, ainda, que o ativismo judicial pode ser considerado uma saída diante da inércia e morosidade dos poderes Executivo e Legislativo em cumprirem suas atribuições em alguns casos, advertindo, contudo, que o ativismo judicial não pode ser entendido como um remédio definitivo para tal problema, mas sim um remédio excepcional nos momentos de crise. ${ }^{36}$ Vejamos:

O ativismo, até aqui, tem sido parte da solução, e não um problema. Mas ele é um antibiótico poderoso, cujo uso deve ser eventual e controlado. Em dose excessiva, há risco de morrer da cura. A expansão do Judiciário não deve desviar a atenção da real representatividade, legitimidade e funcionalidade do poder Legislativo.

\footnotetext{
${ }^{33}$ Cf. FAVOREU, Louis; LLORENTE, Francisco Rubio. El bloque de la constitucionalidad (simposium franco-español de Derecho constitucional). Sevilla: Editorial Civitas; Universidad de Sevilla, 1991. p. 17-34.

${ }^{34}$ RAMOS, Elival. Ativismo judicial, parâmetros dogmáticos. Editora Saraiva, 2015. p. 116-117.

${ }^{35}$ BARROSO, Luís Roberto. Judicialização, ativismo judicial e legitimidade democrática. In: Revista de Direito do Estado, a. 4, n. 13, p. 7191, jan./mar. 2009.

${ }^{36}$ JUNIOR, Arthur Bezerra de Souza; MEYER-PFLUG, Samanta Ribeiro. O ativismo judicial no Supremo Tribunal Federal - Judicial Activism the Federal Supreme Court, p. 7 apud MIARELLI, Mayra Marinho; LIMA, Rogério Montai de. Ativismo Judicial e a efetivação de direitos o Supremo Tribunal federal. Porto Alegre: Sergio Antonio Fabris, 2012. p. 63.
} 
Por sua vez, conforme ensinamentos de Luiz Flávio Gomes, ativismo judicial é "uma espécie de intromissão indevida do Judiciário na função legislativa, ou seja, ocorre ativismo judicial quando o juiz 'cria' uma nova norma, usurpando a tarefa do legislador, quando o juiz inventa uma norma não contemplada nem na lei, nem nos tratados, nem na Constituição". ${ }^{37}$

Demais, o renomado professor distingue o ativismo judicial em duas espécies, quais sejam: a) ativismo judicial inovador, o qual é a criação pelo poder Judiciário de uma norma, de uma regra ou de um direito; b) ativismo judicial revelador, que é a complementação, por parte do poder Judiciário, de um princípio/valor constitucional ou de uma regra lacunosa. ${ }^{38}$

Finalmente, cumpre ressaltar que o excesso do ativismo judicial, ou seja, quando o exercício das atribuições definidas pela Constituição Federal a cada um dos poderes é extrapolado, dá, por vezes, ensejo a uma mutação inconstitucional. Diante disso, o ativismo judicial poderia ofender o ordenamento jurídico em duas situações: a) deformação da normatividade constitucional; b) deformação do Direito infraconstitucional.

Conforme é sabido, o Supremo Tribunal Federal (STF) é o órgão máximo do poder Judiciário brasileiro e possui, entre outras, a função de proteger a Constituição Federal, que é a norma mais importante do país.

Essa proteção, contudo, só ocorre porque encontra-se prevista na própria Constituição Federal, sendo certo que, para alcançá-la, o Supremo Tribunal Federal precisa intervir algumas vezes nos demais poderes (Legislativo e Executivo), bem como na vida social. E é daqui que algumas decisões judiciais proferidas pelo STF extrapolam os limites previstos pela Constituição Federal, dando ensejo, assim, ao ativismo judicial.

A títulos de exemplos, cita-se, primeiramente, a decisão proferida na Arguição de Descumprimento de Preceito Fundamental $n^{\circ} 54$.

Isso porque o artigo 128 do Código Penal dispõe que será autorizada a realização de aborto apenas quando não houver outro meio para salvar a vida da gestante ou quando a gravidez for resultante de estupro. Ou seja, o legislador, ao editar a norma autorizadora para a prática do aborto dispôs, de forma taxativa, as duas únicas hipóteses que autorizariam a prática do referido procedimento.

Na referida Arguição de Descumprimento de Preceito Fundamental no 54, contudo, o Supremo Tribunal Federal, após longos debates, entendeu haver uma terceira hipótese que autorizaria a prática do aborto de forma atípica, qual seja, a realização de aborto no caso de gravidez de feto anencefálico.

Referida decisão foi profundamente criticada por alguns juristas brasileiros, bem como por alguns setores da sociedade civil, haja vista que, para eles, o Supremo Tribunal Federal estaria legislando ao criar uma terceira hipótese que permitisse a realização do aborto de forma atípica, ou seja, o STF estaria invadindo a competência do poder Legislativo.

Aqui, entre os ministros que compunham o quórum da Suprema Corte quando do pronunciamento da referida decisão, cumpre destacar o entendimento do ministro Ricardo Lewandowski, o qual, levando em consideração o ativismo judicial, destacou que não é dado ao poder Judiciário o poder de inovar o ordenamento normativo como se seus integrantes fossem parlamentares eleitos.

No mesmo sentido, a ministra Ellen Gracie, também considerando o fenômeno do ativismo judicial, aduziu não ser possível o poder Judiciário, por meio de um entendimento jurisprudencial, criar uma terceira hipótese que legitimaria o aborto, bem como ressaltou, por fim, que a decisão feria a separação dos poderes e a repartição das competências.

Como segundo exemplo, cumpre destacar a decisão proferida pelo Supremo Tribunal Federal na Ação Direta de Inconstitucionalidade Por Omissão n 26.

Na referida decisão, o Plenário do STF entendeu que houve omissão inconstitucional do Congresso Nacional por não editar uma lei que criminalizasse atos de homofobia e de transfobia, razão pela qual, por maioria, a Corte enquadrou referidos atos como tipo penal definido na Lei do Racismo (Lei 7.716/1989).

\footnotetext{
37 GOMES, Luiz Flávio. O STF está assumindo um "ativismo judicial" sem precedentes? Brasília: Conteúdo Jurídico, 2009. Disponível em: http://www.conteudojuridico.com.br/?artigos\&ver=2. 25162. Acesso em: 7 jul. 2018.

${ }^{38} \mathrm{Ibid}$.
} 
Aqui, mais uma vez o ministro Ricardo Lewandowski fundamentou ser indispensável a existência de lei para que seja viável a punição penal de determinada conduta, destacando, por fim, a necessidade de dar ciência ao Congresso Nacional em relação à mora legislativa sobre o tema. Veja-se: ${ }^{39}$

A extensão do tipo penal para abarcar situações não especificamente tipificadas pela norma incriminadora parece-me atentar contra o princípio da reserva legal, que constitui uma garantia fundamental dos cidadãos que promove a segurança jurídica de todos.

Por sua vez, o ministro Dias Tofolli acompanhou o entendimento do ministro Ricardo Lewandowski, bem como ressaltou, ao final, que apesar da divergência na conclusão todos os votos proferidos repudiaram a discriminação, o ódio, o preconceito e a violência por razões de orientação sexual e identidade de gênero.

Verifica-se, portanto, do entendimento dos ministros supracitados, que as questões referentes aos fetos anencefálicos, homofobia e transfobia, primeiramente, deveriam ser analisadas pelo poder Legislativo, o qual possui a legitimidade para legislar e, por consequência, de acrescentar mais tipos penais, sob pena de estarem extrapolando a função jurisdicional, o que, por sua vez, dá ensejo ao ativismo judicial.

\section{CONCLUSÃO}

Todo o consubstanciado no presente estudo teve como objetivo traçar um entendimento linear que compreende demonstrar a frágil, porém vital, ligação existente entre o tempo e o Direito. As perspectivas de alteração da realidade social, junto ao correr das épocas, altera substancialmente a visão que se tem e a interpretação da Constituição e das normas estruturais do ordenamento, tendo em vista que a sociedade apresenta uma evolução contínua, dinâmica do seu modo de pensar, dos seus valores, etc., enquanto que, por outro lado, as Constituições, vivas que são, devem acompanhar essa evolução sob pena de perder sua eficácia e afastar-se da realidade.

Assim, o fenômeno da mutação constitucional surge como maneira conveniente de alteração e adequação informal do sentido da constituição e extensão de seu alcance, razão pela qual referido fenômeno é essencial para atualizar e adequar a realidade normativa constitucional à realidade fática, social, política, cultural, histórica e econômica. Tal fenômeno, como processo dinâmico que é, acontece de forma tão imprevisível e inevitável quanto às transformações do mundo real.

Por sua vez, devido à tamanha importância desse fenômeno, deve ele ser limitado para que se evitem mutações perigosas ou inconstitucionais a colocar todo o ordenamento jurídico em situação de instabilidade e insegurança. Ou seja, para que haja a utilização da mutação constitucional devem ser respeitados alguns limites que são impostos pela própria natureza da norma, pois, caso contrário, estaremos diante de um ativismo judicial.

Enfim, chega-se à conclusão de que o fenômeno mutação constitucional ora estudado trata-se de uma mudança do sentido e alcance ocorrida no texto normativo por meio de uma nova interpretação da norma realizada pelo Supremo Tribunal Federal no exercício do poder difuso, e que esse fenômeno assume um importante papel na atualização da nossa Constituição, sem o qual a Carta Maior não passaria de uma simples folha de papel.

\section{REFERÊNCIAS}

BARROSO, L. R. Judicialização, ativismo judicial e legitimidade democrática. In: Revista de Direito do Estado, a. 4, n. 13, p. 71-91, jan./mar. 2009.

BOTELHO, N. M. Mutação constitucional: a Constituição viva de 1988. Rio de Janeiro: Lumen Juris Editora, 2011.

BRASIL. Constituição Federal. 1988. Disponível em: http://www.planalto.gov.br/ccivil_03/constituicao/constituicao.htm.

BRASIL. Decreto-Lei $n^{\circ}$ 4.657, de 4 de setembro de 1942. Disponível em: http://www.planalto.gov.br/ccivil_03/decreto-lei/ del4657compilado.htm.

BULOS, U. L. Curso de Direito Constitucional. São Paulo: Saraiva, 2007.

${ }_{39}$ Disponível em: http://portal.stf.jus.br/noticias/verNoticiaDetalhe.asp?idConteudo=414010. 
BULOS, U. L. Costume constitucional. In: Revista de Informação Legislativa. Brasília, a. 33, n. 131, jul./set. 1996. Disponível em: http://www2.senado.leg.br/bdsf/bitstream/handle/id/176479/000512740.pdf?sequence=3.

CANOTILHO, J. J. G. Direito Constitucional. 5. ed. São Paulo: Almedina, 1991.

CARVALHO GOULART, D. V. Mutação constitucional e sua aplicabilidade no ordenamento jurídico brasileiro. Disponível em: https://jus.com.br/artigos/29327/mutacao-constitucional-e-sua-aplicabilidade-no-ordenamento-juridico-brasileiro/1.

CAVEDON, R. Teoria Geral dos Direitos Coletivos. Curitiba: Juruá, 2015.

FAVOREU, L.; LLORENTE, F. R. El bloque de la constitucionalidad (simposium franco-español de Derecho constitucional). Sevilla: Editorial Civitas; Universidad de Sevilla, 1991.

FERRAZ, A. C. C. Processos Informais de Mudança da Constituição. 1. ed. São Paulo: Max Limonad, 1986.

GOMES, L. F. O STF está assumindo um "ativismo judicial” sem precedentes? Brasília: Conteúdo Jurídico, 2009. Disponível em: http://www.conteudojuridico.com.br/?artigos\&ver=2. 25162.

KUBLISCKAS, W. M. Emendas e mutações constitucionais: análise dos mecanismos de alteração formal e informal da Constituição Federal de 1988. São Paulo: Atlas, 2009.

MIARELLI, M. M.; LIMA, R. M. Ativismo judicial e a efetivação de direitos o Supremo Tribunal federal. Porto Alegre: Sergio Antonio Fabris, 2012.

MORAES, A. Direito constitucional. 20. ed. São Paulo: Atlas, 2006.

RAMOS, E. S. Ativismo judicial, parâmetros dogmáticos. 2. ed. São Paulo: Editora Saraiva, 2015.

SCHETTINO, J. G. R. Controle judicial de constitucionalidade e ativismo judicial processual. Rio de Janeiro, 2008. 174p. Dissertação (Mestrado) - PUC-Rio, Departamento de Direito da PUC-Rio, 2008.

SILVA, J. A. Curso de direito constitucional positivo. 33. ed. atual. São Paulo: Malheiros, 2010.

SOUZA NETO, C. P. Direito Constitucional: teoria, história e método de trabalho. 1a reimpressão. Belo Horizonte: Fórum. 2013. 